\title{
Ensinando através de imagens: a linguagem gráfica da apresentação do experimento sobre fotossíntese da planta elódea em livros didáticos brasileiros
}

\author{
Teaching with images: the graphic language used \\ in presenting the experiment on photosynthesis \\ in the elodea plant in Brazilian textbooks
}

experimento, livro

didático, memória gráfica brasileira, linguagem gráfica

\begin{abstract}
As atividades experimentais relatadas em livros didáticos escolares costumam apresentar imagens que complementam a linguagem verbal, auxiliando na demonstração dos materiais, etapas e procedimentos de montagem. Este artigo utilizou os escritos sobre linguagem gráfica do teórico Michael Twyman para analisar 13 imagens que representam um mesmo experimento sobre fotossíntese com a planta elódea, todas elas retiradas de livros didáticos brasileiros publicados em sete décadas do sec. XX e XXI. O artigo foi norteado pelo objetivo de contribuir para a interação entre designers, professores e os demais profissionais envolvidos na criação de materiais didáticos. A análise imagética permitiu relacionar escolhas de design com estratégias pedagógicas. Observou-se, por exemplo, que a abstenção de alguns livros em utilizar imagens compostas por elementos distintos pode originar-se de uma estratégia pedagógica legitimada pela teoria da aprendizagem construtivista.
\end{abstract}

Experimental activities reported in textbooks often have images that complement the verbal language, assisting in the demonstration of materials, steps and procedures. This article has used Michael Twyman's writings on the theory of graphic language to analyze 13 images representing the same experiment on photosynthesis in the water plant elodea. All images were taken from Brazilian textbooks published during seven decades of the $X X$ and $X X I$ centuries. The article's main goal was to contribute to the interaction between designers, teachers and other professionals involved in the creation of learning materials. The analysis of images allowed us to relate design choices with teaching strategies. One of the points observed, for example, was that the reason why some of the textbooks do not use images composed of different elements can originate from a pedagogical strategy legitimated by the theory of constructivist learning. 


\section{Introdução}

1 A reprodução das figuras analisadas, apresentadas neste artigo para fins de estudo e crítica, não constitui ofen-sa aos direitos autorais, de acordo com a Lei no 9.610/98, Art. 46 , inciso III.
Dada a pergunta: Qual é a diferença entre as imagens das figuras 1 e 2, ambas retiradas de livros didáticos que abordam o mesmo experimento sobre fotossíntese? Uma resposta usual certamente indicaria que a primeira foi elaborada com mais cuidado e intencionalidade na forma de cada elemento - o que poderia ser resumido pela expressão 'apuro pictórico'. A segunda imagem, por outro lado, não apresenta o mesmo apuro, já que a imprecisão dos traços prejudica o entendimento de certos elementos como, por exemplo, os pontos pretos no tubo de ensaio, que não são bem sucedidos na representação de bolhas de ar.

A diferença no apuro pictórico é uma característica fácil de ser percebida, mas existem outras informações importantes para a análise da linguagem gráfica de imagens como estas. Este artigo fará uso das variáveis descritas pelo historiador e especialista em linguagem gráfica Michael Twyman para analisar outras imagens do mesmo experimento científico, todas elas encontradas em livros didáticos brasileiros publicados a partir da década de 50.

Figura 1 Ilustração de página inteira (Mello, 1974,:63).

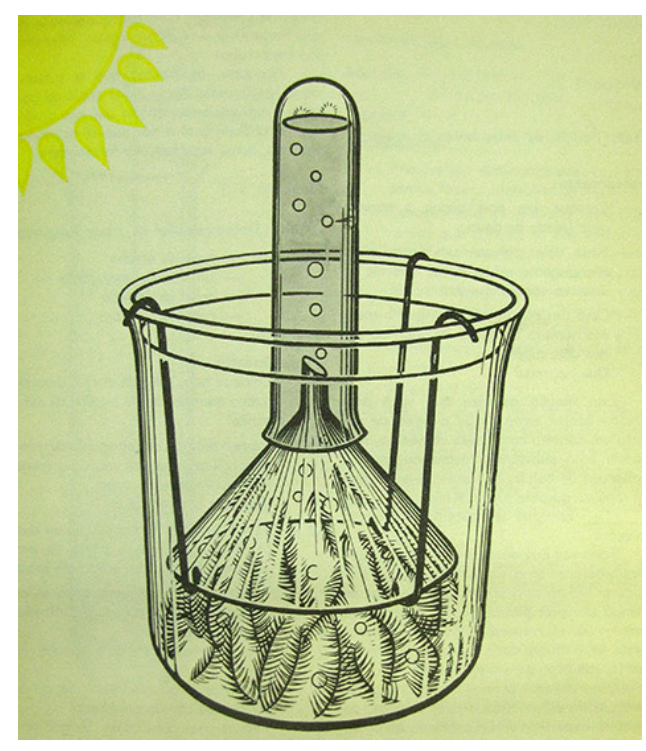


Figura 2 Ampliação de ilustração (Ramos, 1988:15).

2 Mais informações sobre o Projeto Fundão Biologia/UFRJ podem ser encontradas na página: http://www.educacao.ufrj. $\mathrm{br} /$ nec-projetos.html.

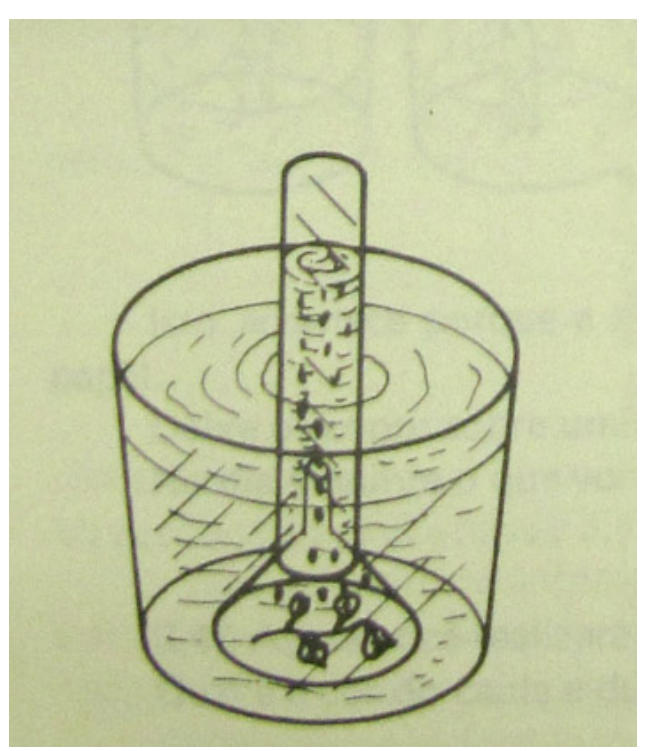

A amostra de imagens analisada foi escolhida segundo os seguintes critérios: 1. Pertencer ao acervo do Projeto Fundão Biologia/UFRJ; 2. Conter uma imagem demonstrativa do experimento sobre fotossíntese com a planta elódea. O Projeto Fundão Biologia/UFRJ foi escolhido enquanto acervo, pois abriga uma coleção histórica de livros brasileiros para o ensino de Ciências e Biologia, incluindo exemplares de difícil acesso. Encontramos 10 livros que atenderam a esses critérios. Foram acrescentados a esta amostra dois outros livros (de 2009 e 2011), que, por serem mais recentes, apresentavam novas características formais que mereciam ser discutidas. Na figura 3, pode-se ver o conjunto de todas as imagens selecionadas para a pesquisa.

A escolha pelo experimento sobre a fotossíntese justifica-se não apenas pela sua importância didática, mas também pela relativa complexidade de sua execução e pelo fato de estar presente em diferentes livros com significativas mudanças na forma de representação. Nota-se que este artigo não pretende apresentar um levantamento de todas as ocorrências do experimento nos livros didáticos brasileiros, mas sim um estudo comparativo de certas imagens. A análise efetuada buscou discutir os elementos esquemáticos, pictóricos e textuais, aplicando conceitos abordados por Michael Twyman tais como estilo, generalidade/particularidade e presença de imagens sinópticas ou imagens compostas de elementos distintos. 
Figura 3 Imagens do mesmo experimento sobre fotossíntese, retiradas de diversos livros didáticos, e organizadas em ordem cronológica, com o correspondente ano de publicação.

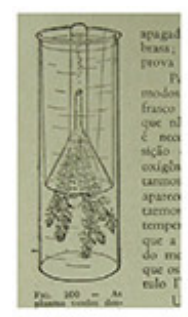

1956

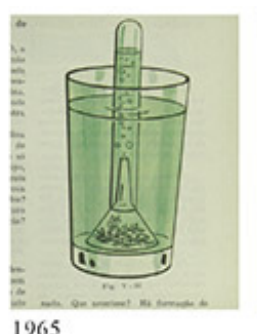

1965

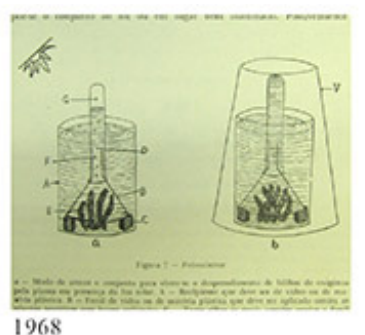

1968

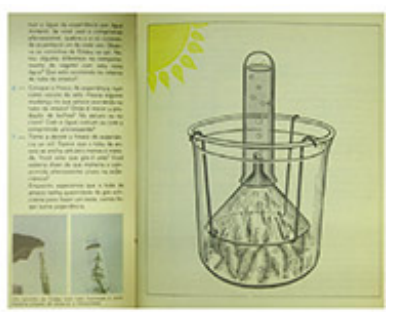

1974

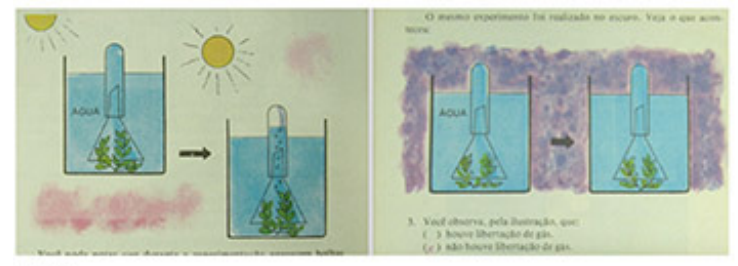

1978
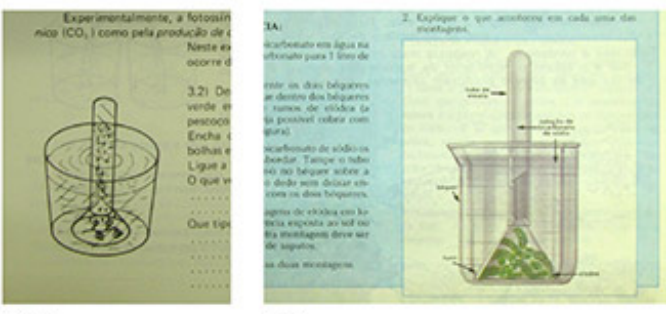

1991

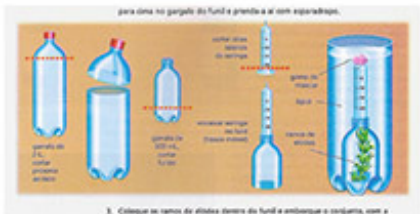

2001

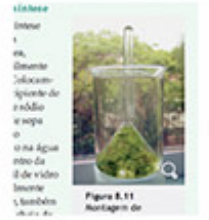

2009

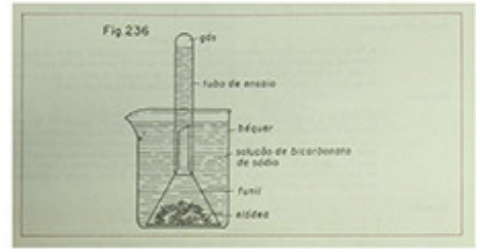

1986

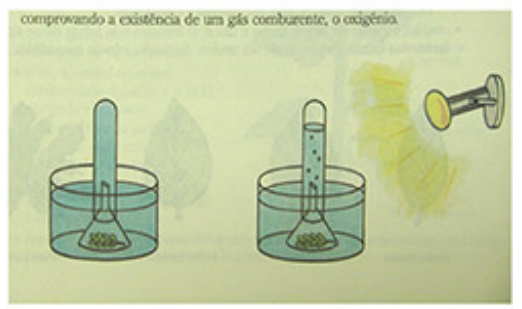

1991
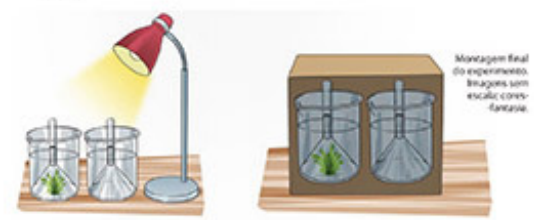

2011

\section{Discussão}

A seguir, apresentamos parte do referencial teórico sobre linguagem gráfica de Michael Twyman, seguido pela análise pictórica das imagens selecionadas, além da proposta de ideias que editores de livros didáticos podem explorar futuramente e considerações finais.

\section{Análise da linguagem gráfica segundo Michael Twyman}

Segundo Twyman, "A linguagem gráfica pode ser subdividida em três categorias: verbal, pictórica e esquemática” (1985: 247). O esquema para estudo da linguagem gráfica proposto pelo autor relaciona modos de simbolização a métodos de configuração (Twyman, 1979). Os primeiros indicam a presença de um ou mais dos seguintes elementos: números, palavras, imagens pictóricas e/ou esquemáticas. 
Assim, os modos de simbolização são subdivididos nos modos: verbal-numérico (palavras e números), pictórico (desenhos e fotografias, em qualquer técnica), pictórico e verbal-numérico (imagens pictóricas, palavras e/ou números), e esquemático (todas as marcas gráficas que não são palavras, números ou figuras).

Já os métodos de configuração dizem respeito à forma pela qual a informação é organizada e distribuem-se em linear puro, linear interrompido, lista, linear ramificado, matriz e não linear. Alguns destes métodos de configuração serão exemplificados à frente.

Twyman também aborda conceitos como: descrição/narração, generalidade/particularidade, persuasão, imagens sinópticas e imagens compostas de elementos distintos, credibilidade, contexto cultural, usuário, estilo, verossimilhança e dimensão temporal, dentre muitos outros. Como foi dito, serão abordados neste artigo principalmente questões de estilo, de generalidade/particularidade e de presença de imagens compostas de elementos distintos. A principal obra de referência utilizada é o capítulo: "Using Pictorial Language: A Discussion of the Dimensions of the Problem" (Twyman, 1985), que foi esmiuçada em língua portuguesa na dissertação de Ricardo Cunha Lima (2009), também utilizada enquanto fonte.

\section{Parêntese sobre o experimento com a planta elódea}

Antes de ser iniciada a análise das imagens, faz-se necessário um breve parêntese para esclarecer o funcionamento do experimento. Direcionado ao ensino da fotossíntese, o experimento propõe a observação da planta elódea imersa em água e posicionada conforme mostram as figuras.

Iluminando-se a planta, é possível ver após certo tempo pequenas bolhas que sobem pelo funil e geram um acúmulo de gás no topo do tubo de ensaio, o que comprova que as plantas desprendem oxigênio durante a fotossíntese (quando moléculas de água combinam-se com moléculas de gás carbônico, formando glicose e oxigênio). Muitos dos livros também recomendam diluir bicarbonato de sódio na água, a fim de enriquecer o meio em gás carbônico e acelerar o resultado.

Ao contribuir na aprendizagem de um processo a princípio invisível, este experimento apresenta grande potencial didático e permite que os alunos construam o conhecimento a partir da interpretação das suas próprias observações, evitando que simplesmente recebam informações prontas.

\section{Análise pictórica das imagens}

Ambas as figuras 4 e 5 pertencem à renomada coleção didática "Iniciação à Ciência" e são destacadas para abordagem da variável 'estilo'. Nelas, é interessante observar as diferenças tanto no estilo da linguagem verbal quanto na linguagem pictórica. Em relação a este segundo tipo de informação, vemos que a ilustração da figura 4 
apresenta traços de espessuras mais uniformes, perspectiva cônica central (único ponto de fuga e uma das faces do objeto situada mais próxima do observador), além de oferecer riqueza de detalhes na representação da planta - o que a aproxima do estilo de ilustração botânica.

Figura 4 Ilustração de livro da coleção “Iniciação à Ciência” (Andrade et al., 1956: 314).

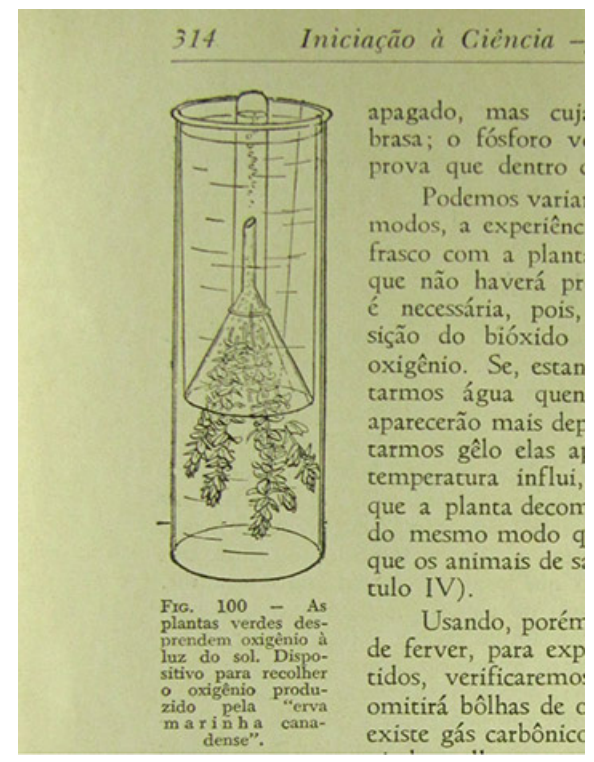

Figura 5 Ilustração de livro da coleção "Iniciação à Ciência” (Instituto de Educação, Ciência e Cultura IBECC - UNESCO, 1965: 183).

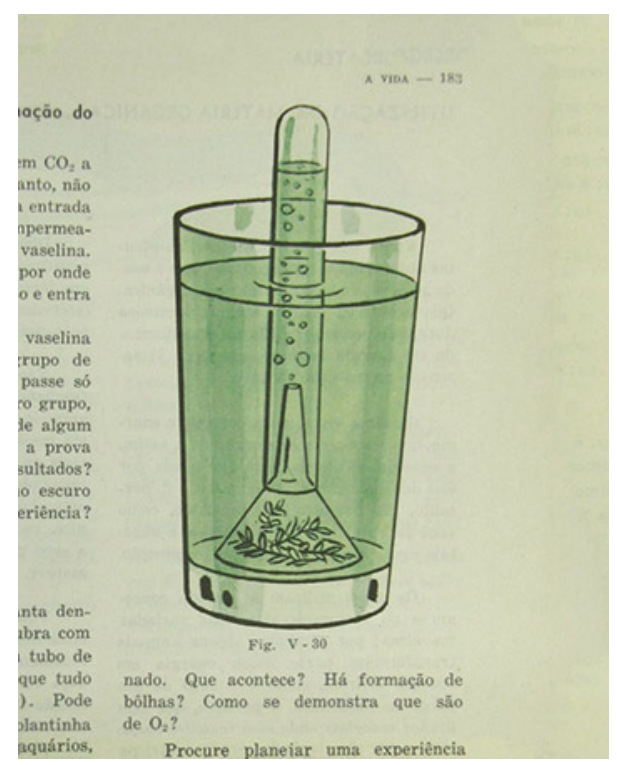

Por outro lado, a figura 5 assemelha-se mais ao estilo dos desenhos em quadrinho: vemos traços e formas estilizadas e simplificadas, como é o caso das manchas negras na base do recipiente (fig. 5.1), além dos dois traços localizados no bico do funil (um aproximadamente verti- 
cal e outro menor, aproximadamente horizontal), que dão o indício simplificado de tridimensionalidade. Soma-se também a utilização de traços de espessuras diferentes e o desenho de bolhas em tamanho exagerado (na experiência real elas são muito pequenas), que aproximam a imagem ao estilo de cartum - estilo este possivelmente mais familiar aos estudantes do que o estilo de ilustração botânica da figura 4 .

Figura 5.1 Detalhes da figura 5 .

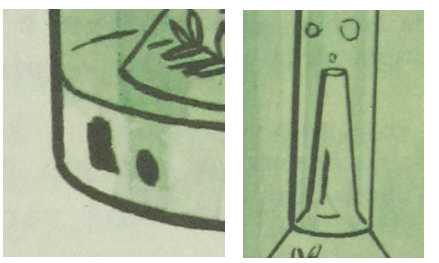

Outra característica relevante a ser analisada nas figuras é o que Twyman chama de 'imagens com elementos distintos'. Esta expressão refere-se a imagens caracterizadas por elementos ou grupos de elementos separados, ou seja, imagens que não se comunicam de forma contínua e unificada (Lima, 2009). A este respeito Twyman pontua, reportando-se a Otto Neurath:

There may (..) be considerable practical difficulties in the production of images composed of discrete elements because it is not as easy as it may seem to describe step by step even a simple operation like making a cup of tea. Such an exercise, which may well require as many as 50 discrete images, is analogous to computer programing and points to the value of using picture language as an exercise in clear thinking (Neurath, 1936) (Twyman, 1985: 271).

Para abordar o tema das imagens com elementos distintos, relacionando-o às imagens selecionadas, é necessário antes considerar a questão do propósito, que não é o mesmo em todas elas. Dos 13 livros consultados, 11 apresentam 'roteiros' do experimento fornecendo instruções para sua montagem - e dois (apresentados mais a frente nas figuras 10 e 11) mostram apenas 'demonstrações' - que explicam visualmente o processo de fotossíntese. Por isso, as imagens dos 'roteiros' e das 'demonstrações' serão analisadas separadamente.

Devido à complexidade da montagem, faz-se importante o uso de imagens que ilustrem o posicionamento e orientação de cada item do material. A maioria dos livros analisados recomenda que a planta seja observada em duas situações: ora iluminada, ora no escuro; o que permite inferir sobre o papel desempenhado pela luz durante a fotossíntese.

Na figura 6 , vemos um roteiro que se valeu de uma imagem composta de elementos distintos, exatamente para poder ilustrar o recipiente em dois momentos: com e sem luz (identificados pelas 
letras 'a' e 'b'). O modo de simbolização apresentado neste caso mistura principalmente elementos pictóricos e esquemáticos, além de contar com letras que identificam os itens do material, explicados na legenda. De acordo com Twyman, os elementos esquemáticos são todos aqueles que não são palavras, números ou figuras que relacionam-se mais diretamente com coisas reais. Portanto, nesta imagem, podemos apontar o sol cortado por uma linha, além das setas e traços que acompanham as letras (fig. 6.1) enquanto elementos esquemáticos.

Figura 6 Ilustração que empregou elementos distintos (Santos, 1968: 133).

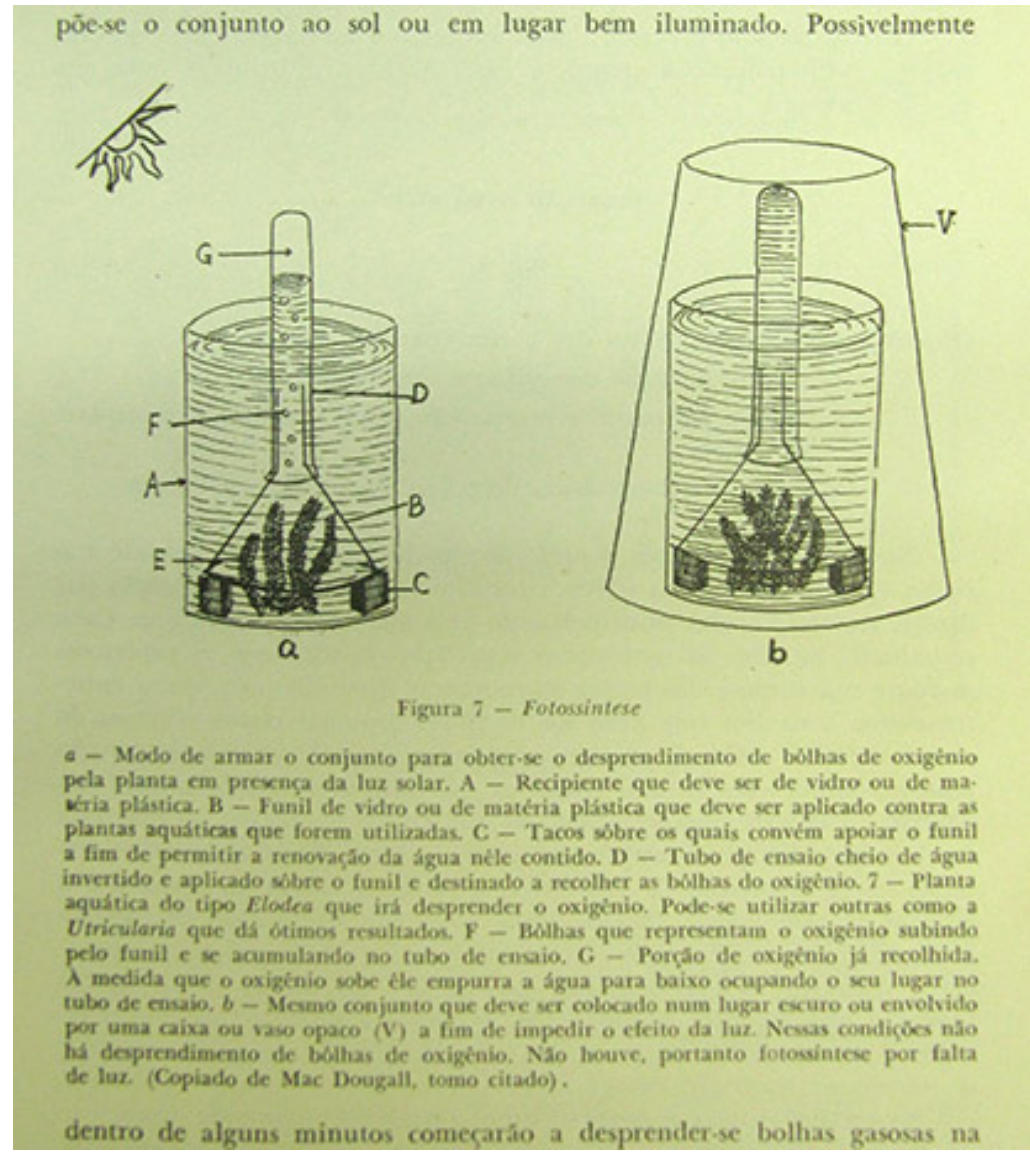

Figura 6.1 Detalhes da fig. 6.
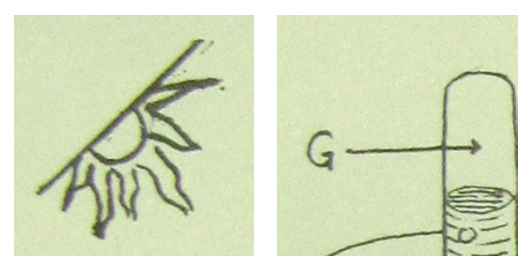
Na parte pictórica, fica visível um problema de comunicação relacionado ao recipiente ' $V$ ', que recobre a montagem 'b'. A utilização de textura para indicar a presença de água contrasta com o desenho sem preenchimento do recipiente, que tende a ser interpretado enquanto transparente, em vez de opaco como se propõe a ser (segundo a legenda, letra V). Na figura 7 , retirada de um livro muito posterior (de 2011), é possível ver uma ilustração que representa a escuridão de maneira mais inteligível.

Figura 7 A representação de um "lugar escuro" para colocação dos recipientes pode ser vista na segunda parte da figura (Bröckelmann, 2011: 197).

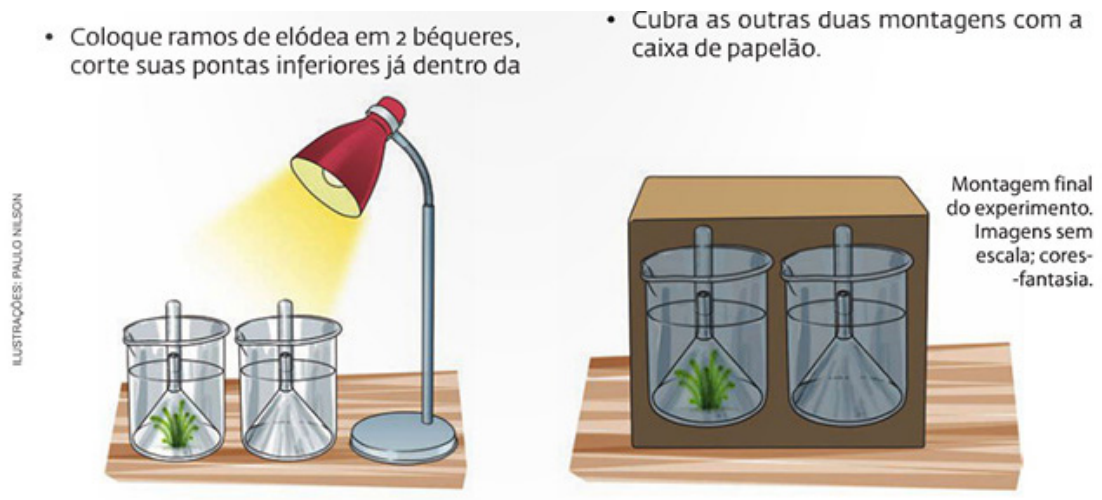

Voltando ao elemento ' $V$ ', da figura 6, nota-se que além de ser útil para destacar a dificuldade de representação da ausência de luz, ele também motiva a reflexão sobre o assunto ao qual Twyman refere-se como 'generalidade' versus 'particularidade'. Segundo o autor, a linguagem pictórica é menos propícia (do que a verbal) à representação de conceitos gerais e neutros. Para explicar tal afirmação, Twyman oferece o exemplo da palavra relógio, que é utilizada para designar todo tipo de dispositivo para se ver o tempo; contudo, seria extremamente difícil fazer uma representação pictórica de um relógio genérico, sem se comprometer, no mínimo, com uma abordagem analógica ou digital.

Da mesma maneira, é difícil desenhar um invólucro que crie o supracitado "lugar escuro" e seja genérico, ou seja, não é fácil desenhar a ideia de uma "caixa ou vaso opaco" (como escrito na legenda da figura 6) de uma só vez. A forma extremamente simplificada escolhida para o vaso indica a possível tentativa de expressar generalidade (afinal, qualquer recipiente grande serviria para a experiência, não seria necessário utilizar somente um vaso ou caixa). Se houve esta tentativa, ela pode ter alcançado um parco sucesso no fato de o vaso poder valer também para um balde, por exemplo, mas o desenho não deixa de ser particular - característica que deve ser sempre considerada, pois é inerente à representação pictórica. 
Tendo demonstrado na figura 6 um exemplo de imagem com elementos distintos, que foi utilizado também para abordar o conceito de generalidade e particularidade, resta agora demonstrar a estratégia de um livro que utilize uma imagem única. Na figura 8 , retirada do livro de 1991, vemos os itens 'discussão', 'etapas da experiência' e 'material' apresentados em linguagem verbal-numérica, acompanhados por uma imagem única, no modo de simbolização pictórico e verbal.

Junto à parte pictórica, os elementos verbais encontram-se dispostos numa configuração 'não linear aberta', o que significa que estão livremente posicionados na imagem, sem ordem de leitura direcionada - permitindo mais de um caminho de leitura.

Figura 8 Roteiro de experimento com imagem única (Cruz, 1991).

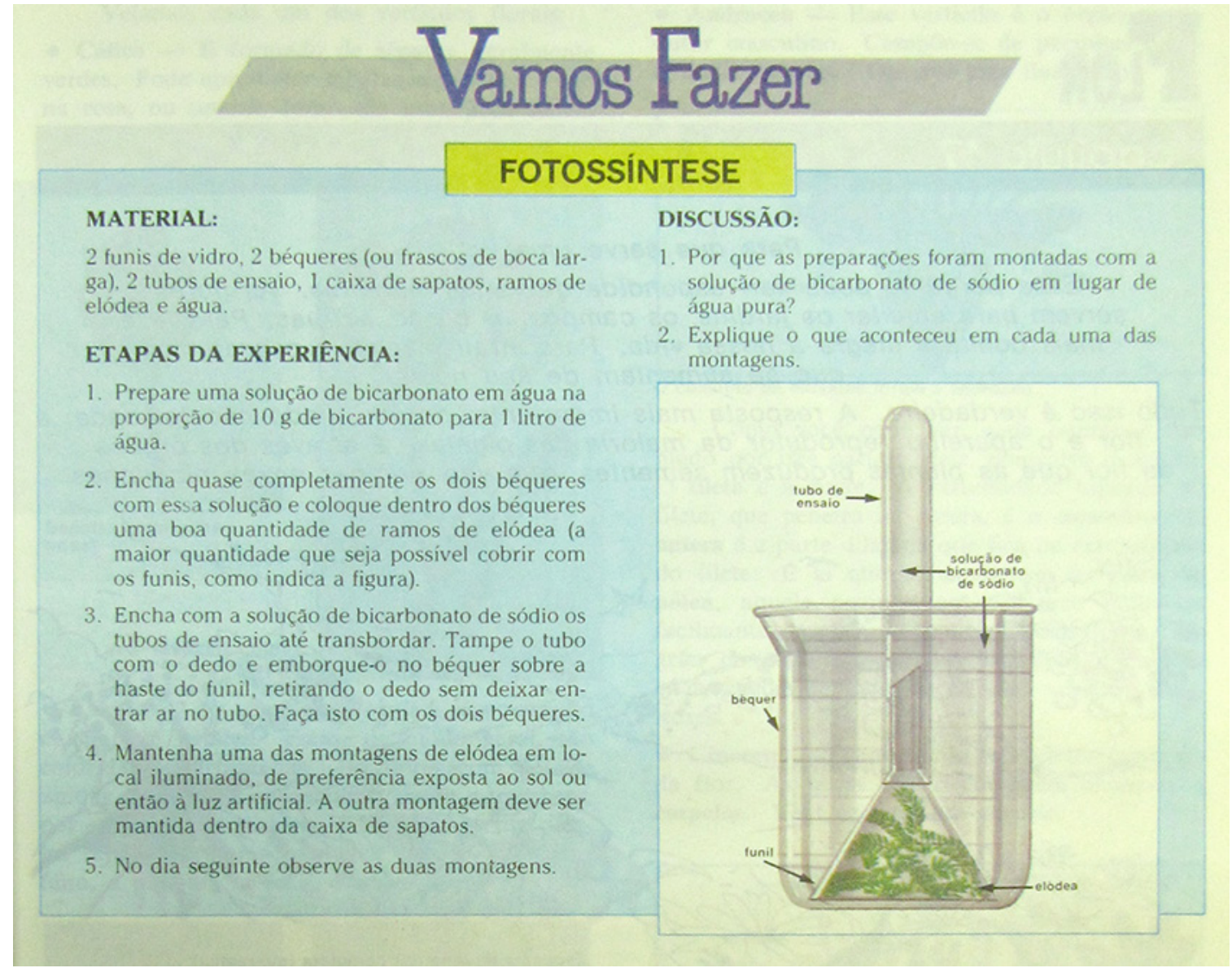

Segundo Twyman, as imagens compostas por elementos distintos tendem à maior eficiência, pois possibilitam mostrar mais de um ponto de vista, além de possibilitarem a incorporação de diferentes escalas, estilos de representação etc. No caso deste experimento, que possui um estágio inicial (sem bolhas nem acúmulo de ar) diferente do estágio final (no qual o gás fica visível no topo do tubo) é natural indagar-se qual seria a vantagem de apresentar o experimento em uma única imagem - como foi feito na figura 8 . 
Mais uma vez, é preciso levar em consideração a questão do propósito da imagem, sempre destacado por Twyman. A abstenção em se utilizar uma imagem composta por elementos distintos pode originar-se de uma estratégia pedagógica, legitimada pela teoria da aprendizagem construtivista. $O$ fato de não se revelar que a planta libera bolhas de oxigênio agrega um elemento de surpresa ao experimento e transforma-o numa atividade que irá gerar perguntas e respostas, ajudando os estudantes a construírem conhecimentos e a tornarem-se ativos no processo de aprendizagem. Neste livro, tal estratégia pedagógica fica clara, já que o resultado do experimento não é revelado nem na linguagem pictórica nem na verbal - característica única dentre os roteiros da amostra pesquisada. Mais adiante, nas figuras 11 e 12, veremos imagens de roteiros que também não revelam o resultado na linguagem pictórica, contudo, o fazem na verbal.

Outra estratégia pedagógica pode ser percebida a partir da análise da figura 9, do exemplar de 1986. Assim como a imagem da figura anterior, esta também não é composta por elementos distintos, mas diferencia-se por indicar de pronto que há gás acumulado no topo do tubo. Mais uma vez, é necessário considerar o propósito da imagem que, neste caso, é o de demonstrar o experimento para professores, e não para alunos (pois este é um manual do professor).

Figura 9 Roteiro de experimento com imagem única que revela o resultado (Funbec, 1986, 326).

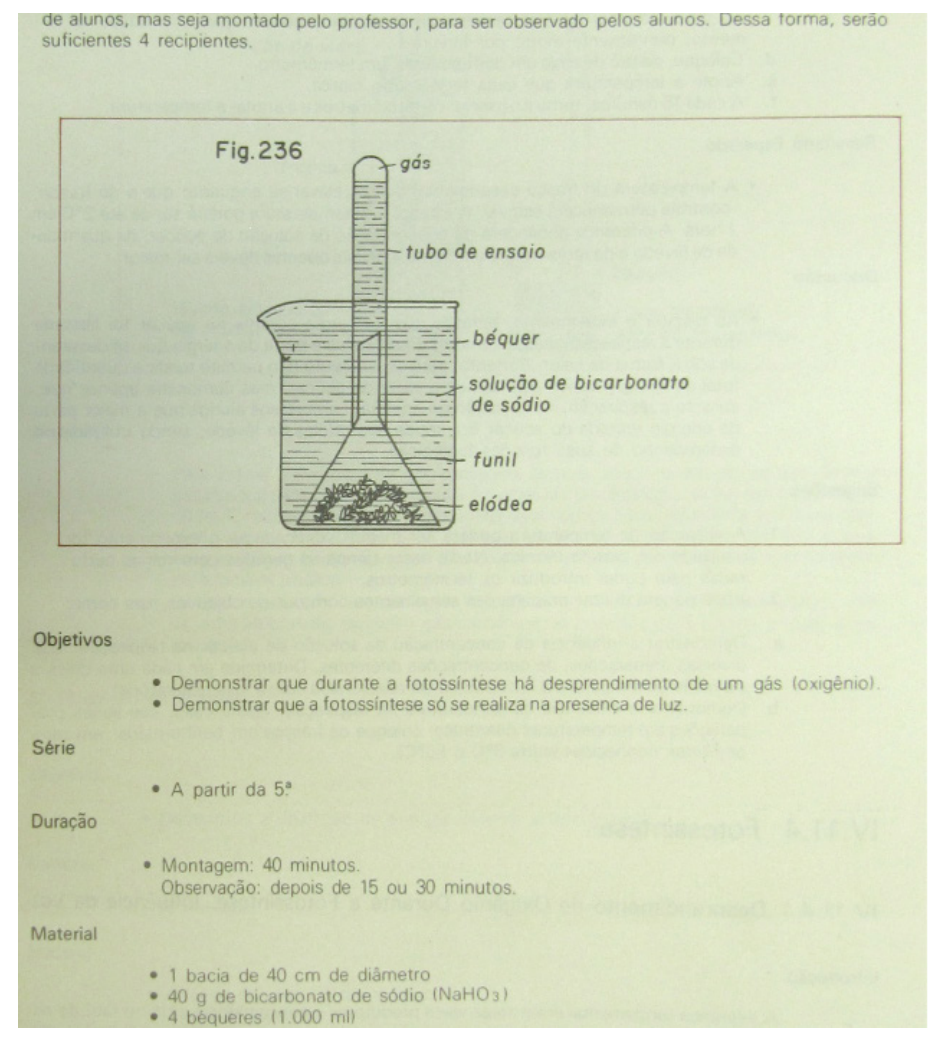

Ainda sobre a figura 9, observamos abaixo do desenho o uso da linguagem verbal-numérica numa configuração de lista, caracterizada 
pela apresentação de unidades semânticas separadas em linhas. Tal configuração é frequentemente utilizada quando existe a necessidade de recolher uma série de materiais (como é o caso também das receitas culinárias) e facilita esta tarefa. Por fim, vemos junto aos elementos pictóricos a utilização de elementos esquemáticos (os traços ao lado esquerdo das palavras) e verbais, também numa configuração de lista, que favorece um único caminho de leitura.

As figuras 10 e 11 pertencem a livros que apresentam o experimento de modo diferente: eles fazem apenas demonstrações, sem de fato sugerir que o aluno faça a montagem e observe os resultados empiricamente. Neste caso, as ilustrações são o único meio pelo qual os alunos terão acesso ao conteúdo ensinado e, portanto, faz-se necessária a utilização de imagens compostas de elementos distintos, de maneira a demonstrar pelo menos a etapa inicial e final do experimento.

Um aspecto interessante da figura 10 (também abordado na análise das figuras 6 e 7) é a solução pictórica para representação da ausência de luz. Por não ser fácil de se representar, muitos dos livros observados referem-se à escuridão apenas na linguagem verbal (por exemplo: "coloque o frasco de experiência num canto escuro (...)" livro da fig. 1, Mello, 1974); mas a linguagem pictórica também é uma opção, como pode ser visto na figura 10, que utiliza uma mancha de cor para este fim.

Figura 10 Demonstração do experimento (Lopes, 1978, p. 50).
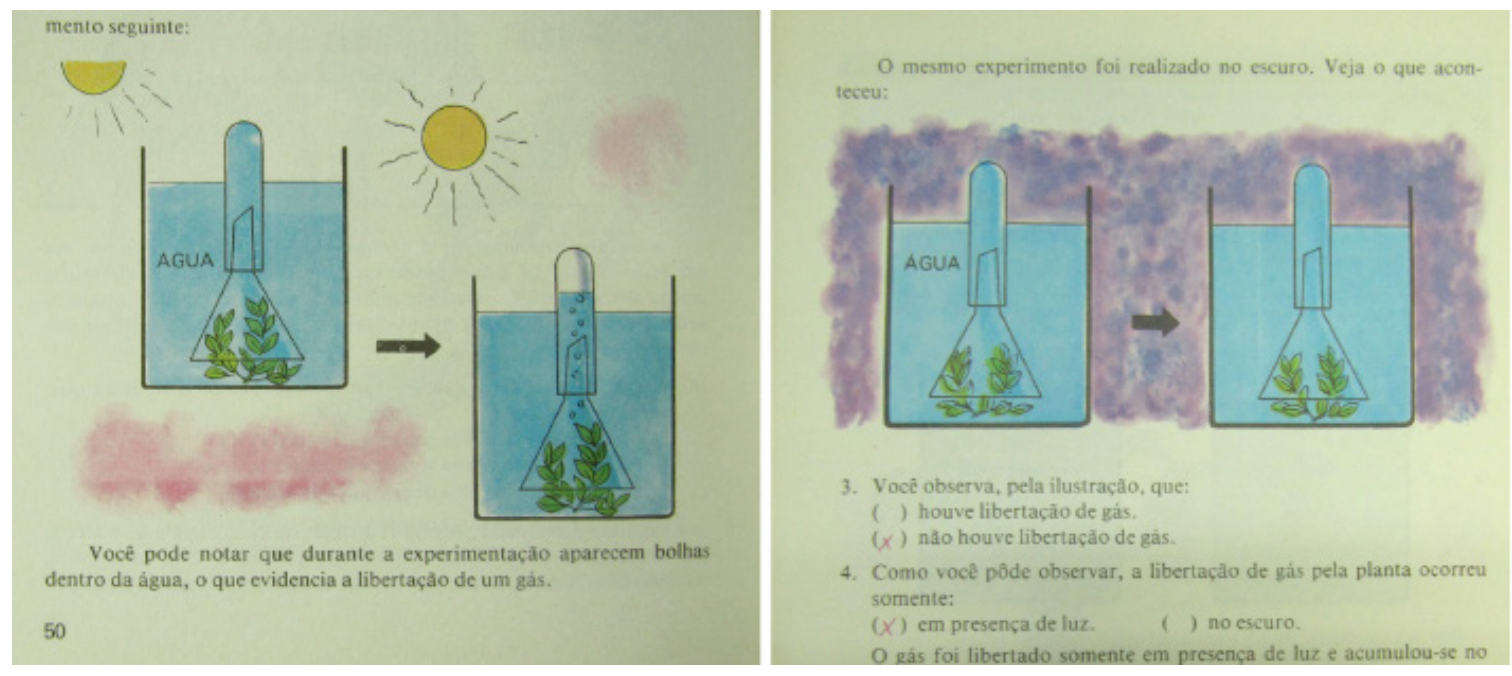

Isolando-se o desenho da segunda página da figura e destituindo-o de explicações verbais sobre o contexto, dificilmente seria possível identificar que a mancha roxa representa a escuridão. Ela poderia facilmente ser confundida com a representação do espaço, do ar, de nuvens ou de fumaça, por exemplo. Contudo, é interessante notar que, estando o desenho disposto ao lado da figura que apresenta o sol, como é feito no livro, a mancha tornase mais compreensível, pois contrapõe-se às pequenas nuvens rosas da primeira figura - ainda que 
continue sendo um elemento de apreensão incerta. Portanto, mesmo ao analisar um elemento específico, é sempre importante considerar o conjunto das imagens no qual se insere, pois certos significados podem emergir apenas quando se estabelece uma comparação com as outras imagens.

Em relação ao estilo pictórico da mesma figura 10, é possível dizer que a ilustração aproxima-se ao estilo dos livros infantis. A bidimensionalidade, a presença de muitas cores, sendo a maioria cores saturadas, além do formato do sol, das bolhas e da planta são elementos que reforçam este estilo. Já na figura 11, com certa similaridade no estilo, destaca-se a extrema simplicidade dos traços, especialmente da planta, e a perspectiva paralela.

Figura 11 Demonstração do experimento (Gowdak, 1991, p.100).

Fotossintese

As plantas são capazes de fabricar seu próprio alimento. Para tanto, além da clorofila - o pigmento verde existente nas folhas -, a planta necessita de luz, água, que retira do solo, e gás carbônico, que retira do ar.

Um sistema bem simples pode ser montado para demonstrar a fotossintese.

Em uma cuba de vidro são colocados água e um ramo de elódea, uma planta aquática. Sobre a planta é posto um funil e sobre ele um tubo de ensaio cheio de água.

O sistema assim montado foi deixado exposto à luz, durante algum tempo. Pequenas bolhas gasosas, saindo dos ramos verdes, foram acumular-se na parte superior do tubo de ensaio.

Para se verificar o tipo de gás ali acumulado, o tubo de ensaio é retirado e nele se introduz um palito de fósforo com a ponta em brasa. O palito se reacende, comprovando a existência de um gás comburente, o oxigênio.
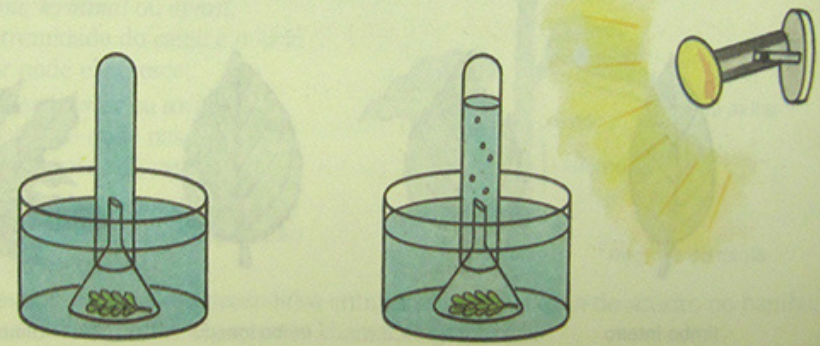

Nota-se também a escolha por representar a água com uma chapada de cor azul que é ao mesmo tempo transparente e opaca - é possível ver no detalhe da fig.11.1 que os traços por trás do tubo de ensaio ficam ocultos, apesar da transparência da água na parte interna do tubo (o mesmo também ocorre na figura 10). 
Figura 11.1 Detalhe da figura 11.

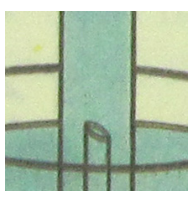

Dentre as imagens coletadas, a que apresenta a maior quantidade de elementos distintos pode ser vista na figura 12. Neste roteiro de experimento, no qual o resultado final é revelado apenas em linguagem verbal, vê-se que o objetivo principal é o de orientar a montagem. A interessante inovação deste livro é a de sugerir o uso de materiais alternativos, de custo radicalmente menor e de fácil acesso, o que suprime a restrição de se possuir um laboratório equipado.

O roteiro sugere a substituição de objetos originalmente de vidro por duas garrafas pet e uma seringa. Contudo, a imagem elaborada para comunicar o procedimento de montagem não é tão clara quanto poderia ser. O maior problema relaciona-se à opção por apresentar a mesma garrafa (de $2 \mathrm{~L}$ ) em duas escalas distintas, enquanto existe também outra garrafa (de $500 \mathrm{~mL}$ ), representada com uma ilustração muito similar. A variação de escalas muitas vezes é imprescindível e não resulta em problemas de compreensão, mas neste caso ela não seria necessária, já que o segundo desenho da garrafa de $2 \mathrm{~L}$ torna o primeiro supérfluo. Por si só, o segundo desenho claramente comunica que a garrafa foi cortada.

Figura 12 Roteiro de experimento com materiais alternativos (Frota-Pessoa, 2001: 34)

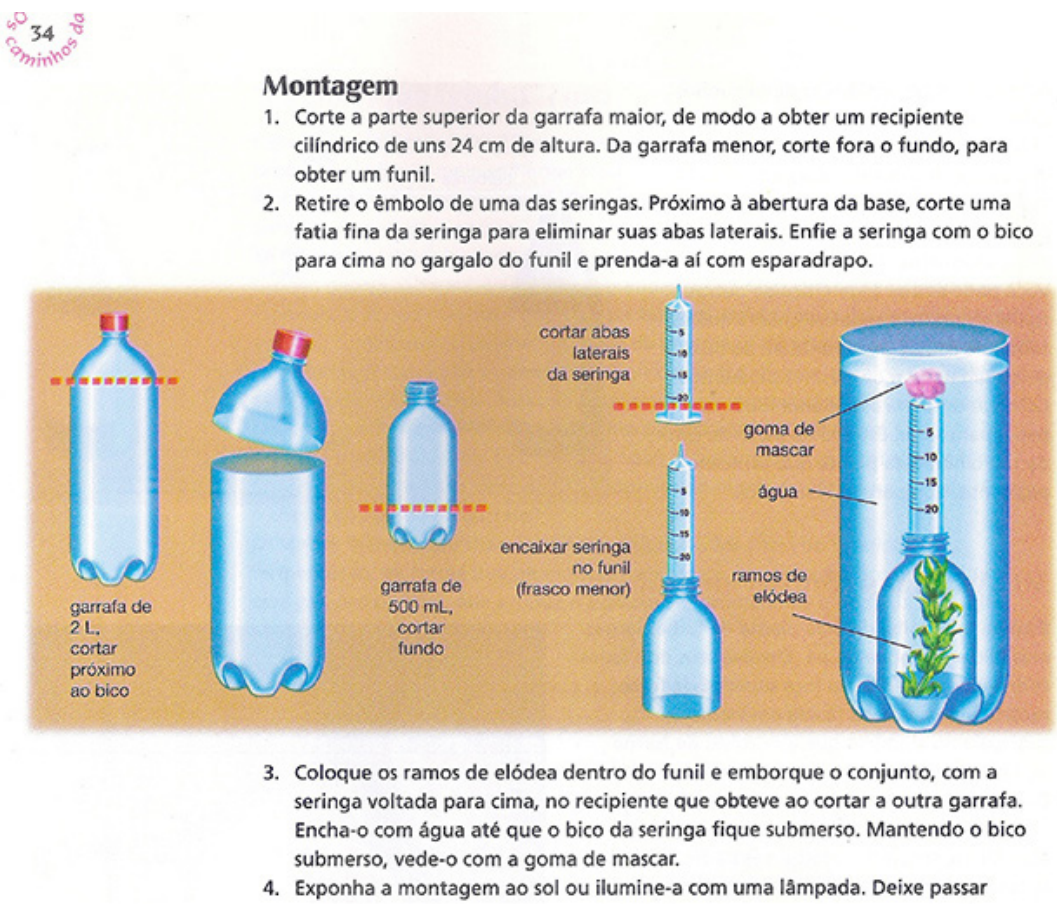


A última imagem analisada, da figura 13, pertence a um livro digital publicado em 2009 e destaca-se por ser a única imagem desta amostra a utilizar uma fotografia em vez de uma ilustração. Tal fotografia é fiel à realidade e comunica objetivamente a aparência dos materiais utilizados, contudo, neste caso, o uso do registro fotográfico não implica numa compreensão mais efetiva da totalidade do processo. Além de ser menos descritiva do que imagens que mesclam elementos verbais e esquemáticos, ela também é menos narrativa do que as que fazem uso de elementos distintos.

Figura 13 Roteiro de experimento com utilização de fotografia (Amabis et al., 2009, p. 255).
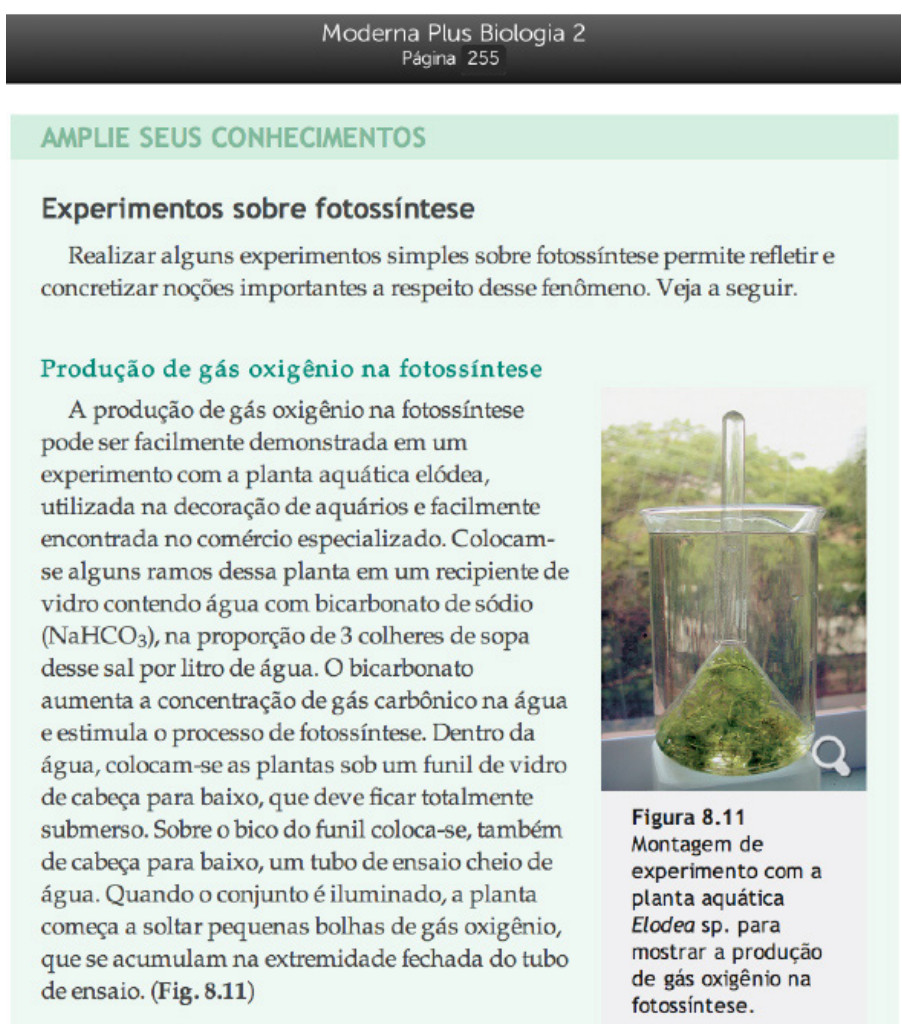

Figura 8.11

Montagem de experimento com a

planta aquática

Elodea sp. para

mostrar a produção de gás oxigênio na fotossíntese.

Em se tratando de um roteiro de experimento (é possível ler no primeiro parágrafo da figura que os alunos são orientados a realizar o experimento), o procedimento de montagem poderia ser retratado de maneira mais clara. A escolha pelo estilo fotográfico não exclui a possibilidade de se fazer a produção da imagem de forma a intencionalmente destacar características importantes, como o fato de que o tudo de ensaio deve estar inicialmente repleto de água - o que não fica claro na fotografia e poderia induzir ao erro. De maneira a remediar a situação, seria possível utilizar um fundo uniforme (como cartolina ou parede de cor contrastante), ou uma gota de corante azul na água, por exemplo. Uma alternativa para se manter o fundo de árvores (já que ele sugere a positiva continuidade entre o processo experimental e o que ocorre na natureza), seria a de se inserir elementos verbais e esquemáticos que esclarecessem as características pouco visíveis. 


\section{Ideias a explorar futuramente}

A figura 14, retirada do texto de Twyman (1985, p.272), é útil para abordar duas ideias potenciais que merecem ser exploradas por designers e ilustradores de livros didáticos. A primeira é a da nãolinearidade na organização dos elementos, que pode ser vista nesta figura e tem como resultado o abarcamento de diversos caminhos de leitura. No caso pesquisado, a vantagem estaria na inclusão paralela de diversos detalhes sobre a montagem, o que tornaria o procedimento mais claro sem contudo fornecer uma ordem cronológica que deixaria a composição demasiadamente explicativa e simplista. A segunda ideia digna de ser explorada é a maior integração entre elementos verbais, esquemáticos e pictóricos, que também pode ser vista na figura 14, e permite fazer uso das particularidades e vantagens dos três tipos de linguagens.

Figura 14 Ilustração retirada dos arquivos do jornal britânico Sunday Times, que figura no texto de Twyman, 1985.

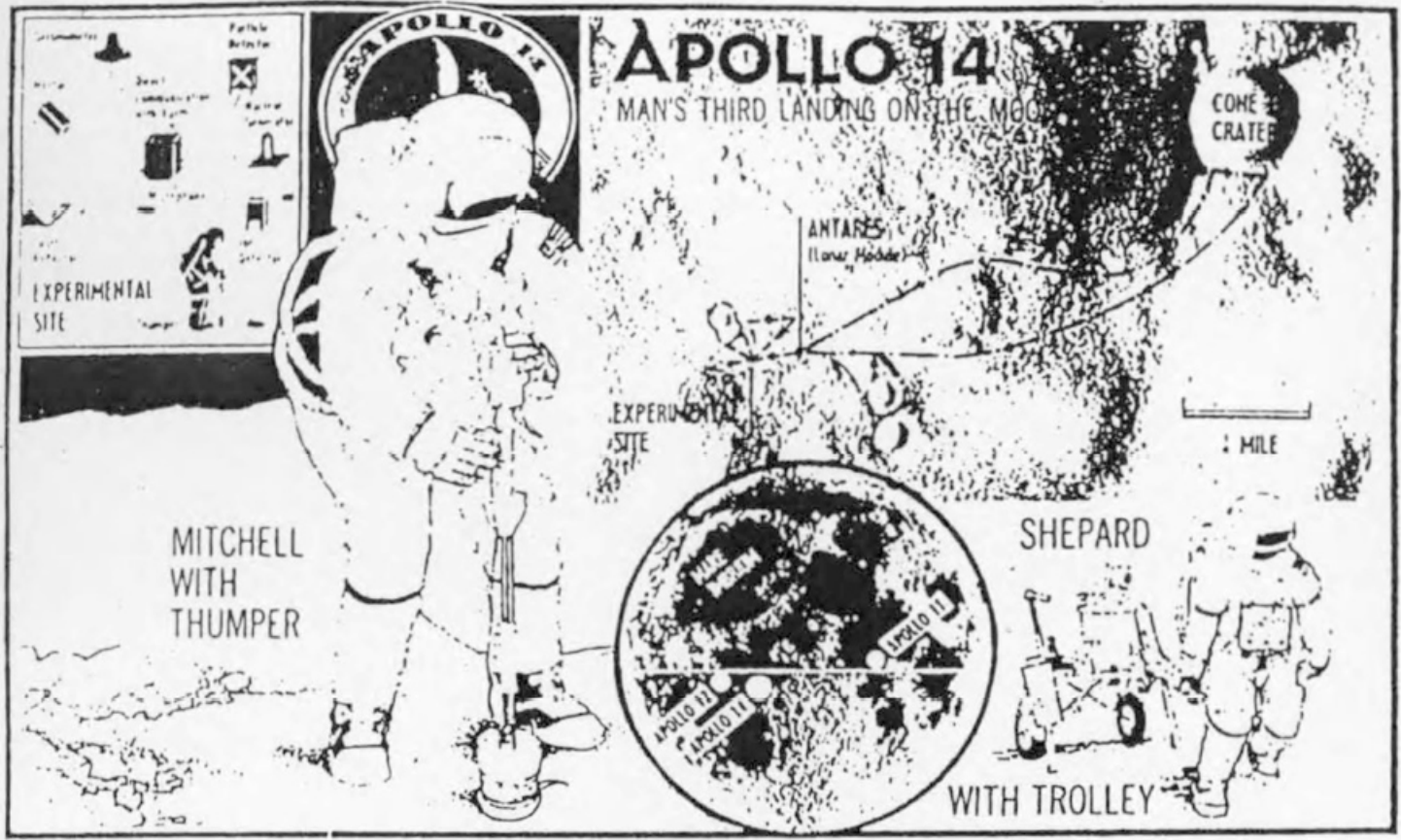

Fig. 27. Newspaper illustration of the Apullu is moon landing: fi consists of a number of diserete inages, all to differeni seales, and has nu clear scyuence of reading. Frum the Sunduy Times arehives

No caso pesquisado, por exemplo, a exploração destas duas ideias poderia resultar numa imagem que integrasse, dentre outros, os seguintes elementos: (1) o material utilizado apresentado em pequenos pictogramas, dispostos no formato de lista ou matriz, (2) o título, (3) o desenho da montagem inicial, (4) uma lupa com a ampliação da folha de elódea com pequenas bolhas ao redor, (5) a equação $\mathrm{CO}_{2}+\mathrm{H} 2 \mathrm{O}+$ Energia luminosa = ? (6) a legenda "Exposição 
à luz" junto à ilustração do sol, tendo abaixo dela a montagem experimental e raios de luz ligando os dois elementos; e a legenda "Bloqueio da luz" junto à mesma ilustração do sol, mas com a montagem experimental posicionada em um quadrado preto ou hachurado.

\section{Considerações finais}

É evidente a importância de imagens que ilustram os experimentos científicos nos livros didáticos. O primeiro contato entre os estudantes e a matéria muitas vezes é feito através destas imagens - no ato de se folhear o livro, antes mesmo da aula - e elas ajudam a explicitar a aparência de equipamentos, substâncias e transformações, além de demonstrarem etapas temporais e informações de difícil abstração. Contudo, estas imagens também podem conter elementos marcados pela falta de apuro, que poderão prejudicar a compreensão.

Ao longo deste artigo, observamos como a linguagem pictórica tende a ser menos neutra que a verbal. No caso dos experimentos didáticos, isto pode levar o estudante a acreditar que deve utilizar apenas os materiais apresentados pelas ilustrações em situações nas quais outros, talvez mais acessíveis, poderiam ser utilizados. Também foi destacada a dificuldade em se demonstrar na linguagem pictórica certas informações como a ausência de luz, por exemplo, além do fato de as imagens poderem se beneficiar da incorporação de elementos verbais que comuniquem dados invisíveis (como a presença de bicarbonato de sódio na água). Em relação às estratégias pedagógicas explicitadas, observou-se como as imagens podem entregar ou não o resultado dos experimentos. Desta maneira, elas aproximam-se ou afastam-se do modelo de aprendizagem construtivista, na medida em que preservam ou eliminam a possibilidade do estudante criar suas próprias conclusões e surpreender-se na hora de realizar o procedimento.

Espera-se que a realização de outros trabalhos de análise de imagens beneficie a produção de materiais didáticos brasileiros e amplie o diálogo entre os diferentes profissionais envolvidos nesta produção. Ao reunir imagens de difícil acesso, retiradas de livros que saíram de circulação, este artigo alinha-se com o estabelecimento de uma memória gráfica dos livros didáticos brasileiros. 


\section{Referências}

AMABIS, J. M. \& MARTHO, G. R. 2009. Biologia. 3. ed. São Paulo: Editora Moderna, v.2.

AMABIS, J. M. \& MARTHO, G. R. 2009. Biologia. Livro Digital, 3. ed. São Paulo: Editora Moderna. Disponível em <http://viewer.moderna.com.br/viewer.html ?publicationId=FF808081435106A601436CE4871965A4\&publicationVersionId= FF808081442E8E0601442FC3E448018C\#/1>. Acesso em 20 jan. 2015. v. 2.

ANDRADE, E.N.C. \& HUXLEY, J. 1956. Iniciação à Ciência. Tradução de José Reis. 2. ed. Rio de Janeiro: MEC. v. 1.

BRÖCKELMANN, R. H. 2011. Observatório de Ciências $7^{0}$ ano. 1. ed. São Paulo: Editora Moderna.

CRUZ, D. 1991. Os Seres Vivos: Programa de Saúde - Ecologia. 12ª ed. [S.1.]: Editora Ática.

FARIAS, P. L. 2014. On graphic memory as a strategy for design history. In: BARBOSA, H.; CALVERA, A. Tradition, transition, trajectories: major or minor influences? [= Proceedings of the 9th International Committee for Design History and Design Studies]. Aveiro: UA Editora.

FROTA-PESSOA, O. 2001. Os caminhos da vida: biologia no ensino médio: estrutura e ação. São Paulo: Scipione.

FUNBEC. 1986. Laboratório básico polivalente de ciências para o $1^{\circ}$ grau: manual do professor / Fundação Brasileira para o Desenvolvimento do Ensino de Ciências. 2. ed. Rio de Janeiro: FAE.

GOMES, M. M.; SELLES, S. E. \& LOPES, A. C. 2013. Currículo de Ciências: estabilidade e mudança em livros didáticos. Educação e Pesquisa, vol. 39, n.2: 477-492. São Paulo: Universidade de São Paulo.

GOWDAK, D. \& DE MATTOS, N. S. 1991. Aprendendo Ciências, 6: seres vivos, saúde, ecologia. São Paulo: FTD.

INSTITUTO DE EDUCAÇÃO, CIÊNCIA E CULTURA IBECC - UNESCO. 1965. Iniciação à Ciência: Parte 1. Editora Universidade de Brasília.

LIMA, R. C. 2009. Análise da infografia jornalística. Rio de Janeiro: Dissertação (Mestrado em Design) - ESDI/UERJ.

LOPES, P. C. 1978. Ciências, $5^{\underline{a}}$ série, $1^{\underline{o}}$ grau. São Paulo: Saraiva.

LORENZ, K. M. 2008. Ação de instituições estrangeiras e nacionais no desenvolvimento de materiais didáticos de ciências no Brasil: 1960-1980. Revista Educação em Questão, Natal, v.31, n.17, p.o7-23.

MELLO, P. Q. N. 1974. Ciências físicas e biológicas. Rio de Janeiro: MEC / FENAME.

RAMOS, L. A. M. \& BLANCO, R. L. D. 1988. Ciência Experimental. [S.1.]: Mercado Aberto.

SANTOS, N. D. 1968. Práticas de Ciências: Guia de Ensino Elementar. 3. ed. Rio de Janeiro: Olímpica.

SIMÕES, A. S. 2011. Contribuições de técnicas construtivistas no ensino de engenharia de produção. Dissertação (Mestrado em Engenharia de Produção) Centro de Tecnologia, Universidade Federal da Paraíba, João Pessoa.

TUFTE, E. R. 2001. The Visual Display of Quantitative Information. Cheshire: Graphic Press. 
TWYMAN, M. A. 1979. Schema for the Study of Graphic Language. In: KOLERS, $P$. A.; WROLSTAD, M.E. \& BOUMA, H. The Processing of Visible Language. Nova York: Plenum, v. 1. p. 117-150.

TWYMAN, M. 1985. Using Pictorial Language: A Discussion of the Dimensions of the Problem. In: DUFTY, T.M; WALKER, R. Designing Usable Texts. [S.1.]: Academic Press. p. 245-312.

\title{
Sobre as Autoras
}

\author{
Alice Garcia-Gomes, \\ Ensinando através de imagens: a linguagem gráfica da apresentação do \\ experimento sobre fotossíntese da planta elódea em livros didáticos \\ brasileiros. Universidade Estadual do Rio de Janeiro: É formada em \\ Programação Visual e Projeto de Produto pela ESDI/UERJ (2010) e \\ atualmente é bolsista da Capes no programa de mestrado da mesma \\ instituição. Recentemente apresentou o trabalho "Objetos digitais \\ de aprendizagem e o estímulo à investigação científica” (que será \\ publicado nos anais do 1 은 SPGD ESDI). \\ <alicegarciagomes@gmail.com>
}

\section{Edna Lucia Oliveira da Cunha Lima,}

Ensinando através de imagens: a linguagem gráfica da apresentação do experimento sobre fotossíntese da planta elódea em livros didáticos brasileiros.

Pontifícia Universidade Católica do Rio de Janeiro: Possui graduação em Comunicação Visual (UFPE, 1979), mestrado em Design (PUC-Rio, 1998) e doutorado em Comunicação pela Universidade Federal do Rio de Janeiro (2003). Atualmente é professora adjunta na PUC-Rio. Participou do PROCAD-CAPES "Memória gráfica brasileira: estudos comparativos de manifestações gráficas nas cidades do Recife, Rio de Janeiro e São Paulo".

Artigo recebido em 06 abr. 2015, aprovado em 19 dez. 2015. 